\title{
Active children are less adipose and insulin resistant in early adolescence; evidence from the Mysore Parthenon Cohort
}

Sarah H. Kehoe ${ }^{1^{*}}$ (D), Ghattu V. Krishnaveni ${ }^{2}$, Sargoor Veena ${ }^{2}$, Krishnarajasagara N. Kiran ${ }^{2}$, Samuel C. Karat ${ }^{2}$, Asha Dhubey ${ }^{2}$, Patsy Coakley ${ }^{1}$ and Caroline H. D. Fall ${ }^{1}$

\begin{abstract}
Background: The aim of this study was to determine whether physical activity volume and intensity in midchildhood and early adolescence were associated with cardiometabolic risk factors at 13.5 years.

Methods: Participants were recruited from the Mysore Parthenon observational birth cohort. At ages 6-10 and 1113 years, volume and intensity of physical activity were assessed using AM7164 or GT1M actigraph accelerometers worn for $\geq 4$ days, and expressed as mean counts per day and percentage time spent in light, moderate and vigorous physical activity according to criteria defined by Evenson et al. At 13.5 years, fasting blood samples were collected; lipids, glucose and insulin concentrations were measured and insulin resistance (HOMA) was calculated. Systolic and diastolic blood pressure were measured th the left arm using a Dinamap (Criticon). Anthropometry and bio-impedance analysis were used to assess body size and composition. Metabolic and anthropometric measures were combined to produce a metabolic syndrome risk score.

Results: At 6-10 years, boys and girls respectively spent a median (IQR) of $1.1(0.5,2.0) \%$ and $0.8(0.4,1.3) \%$ of recorded time vigorously active. At $11-13$ years, boys and girls respectively spent a median (IQR) of $0.8(0.4,1.7) \%$ and $0.3(0.1,0.6) \%$ of time vigorously active. All of the physical activity parameters were positively correlated between the 6-10 year and the 11-13 year measurements indicating that physical activity tracked from childhood to early adolescence. There were no associations between physical activity at 6-10 years and individual 13.5 year risk factors but \% time vigorously active was inversely associated with metabolic syndrome score $(\mathrm{B}=-0.40,95 \% \mathrm{Cl}$ $-0.75,0.05)$. Volume of physical activity at 11-13 years was inversely associated with 13.5 year HOMA and fat percentage and vigorous physical activity was associated with HOMA, fat percentage, sum of skinfolds, waist circumference and total: HDL cholesterol ratio. Vigorous physical activity was inversely associated with metabolic syndrome score $(B=-0.51,95 \% \mathrm{Cl}-0.94,-0.08)$.

Conclusions: Volume and intensity of physical activity in early adolescence were negatively associated with metabolic and anthropometric risk factors. Interventions that aim to increase adolescent physical activity, especially vigorous, may prevent cardiometabolic disease in later life.
\end{abstract}

Keywords: Adolescent, Cardiometabolic risk, Children, India, Insulin resistance, Physical activity

\footnotetext{
* Correspondence: sk@mrc.soton.ac.uk

${ }^{1}$ Medical Research Council Lifecourse Epidemiology Unit, Southampton

General Hospital, Tremona Road, Southampton SO16 6YD, UK

Full list of author information is available at the end of the article
}

(c) The Author(s). 2019 Open Access This article is distributed under the terms of the Creative Commons Attribution 4.0 International License (http://creativecommons.org/licenses/by/4.0/), which permits unrestricted use, distribution, and reproduction in any medium, provided you give appropriate credit to the original author(s) and the source, provide a link to the Creative Commons license, and indicate if changes were made. The Creative Commons Public Domain Dedication waiver (http://creativecommons.org/publicdomain/zero/1.0/) applies to the data made available in this article, unless otherwise stated. 


\section{Background}

Cardiovascular disease (CVD) was the leading cause of death and disability globally in 2017 [1]. It has been estimated that in India deaths attributable to cardiovascular causes will increase from 2.7 million in 2004 to 4 million in 2030 [2]. Diabetes is a risk factor for CVD and in 2015 worldwide diabetes prevalence was estimated at 415 million. It is predicted to increase to 642 million by 2040 [3].

There is heterogeneity between middle income countries in terms of the burden of cardiometabolic disease. However, three quarters of people with diabetes live in low- and middle-income countries and there is a particularly high burden in South Asia. For example, 9\% of the Indian population aged 20-79 have type 2 diabetes and there is evidence that there is a further proportion who are undiagnosed or have impaired glucose tolerance [3]. The increase in childhood overweight and obesity [4-6] is thought to contribute to the increase in cardiometabolic disease prevalence in India.

There is evidence from studies in South Asia and among children of South Asian origin living in the UK that excess body fat and abdominal adiposity are risk factors for insulin resistance and type 2 diabetes [7]. In addition, insulin metabolism among children of South Asian origin living in the UK appears to be more sensitive to adiposity than among their white Caucasian counterparts [8]. The effect of adiposity on insulin metabolism appears to occur earlier in childhood among those of South Asian origin [9]. These findings indicate that South Asian children and adolescents may be at particularly high risk of becoming insulin resistant and developing type 2 diabetes in later life.

Insufficient physical activity has been suggested as one of the causes of the increase in cardiometabolic disease in India [2]. There is some evidence from European and North American studies that increased physical activity is associated with reduced risk factors for cardiometabolic disease including insulin resistance [10-12] and that sedentary time is positively associated with cardiometabolic risk [13]. There is inconsistent evidence on the association between physical activity and blood pressure and blood lipids in childhood [14]. Research in a European cohort found an inverse association between vigorous physical activity in childhood and a composite score of cardiometabolic disease risk in adolescence [15].

Physical activity, as a behaviour has been found to track from childhood into adulthood with adolescence being a critical time for maintenance of physical activity particularly for girls $[16,17]$. It is thought that girls may become less active in adolescence due to onset of menarche and cultural factors that make physical activity less desirable. Interventions that can address these factors and encourage adolescents to maintain physical activity may be helpful in preventing cardiometabolic disease. A recent study investigated several components of physical activity behaviour and infrastructure among 49 countries and found that there was variability in physical activity levels among children and adolescents. In general, middle income countries scored lower than high income countries with India being ranked in the bottom 10 out of 49 [18].

To our knowledge no studies have investigated longitudinal associations between objectively measured physical activity and risk factors for later cardiometabolic disease among children or adolescents in India. Our objectives were to study (1) trends in physical activity with age and (2) longitudinal associations between physical activity in childhood and early adolescence and risk factors including insulin resistance, body fat percentage, skinfold thicknesses, waist circumference, waist hip ratio, blood lipids and blood pressure at 13.5 years in a South Indian birth cohort. Our hypothesis was that participants who were more physically active in childhood and early adolescence would be at lower risk of cardiometabolic disease at 13.5 years.

\section{Methods}

\section{Study design and setting}

We used longitudinal data from an observational birth cohort study named the Mysore Parthenon Birth Cohort [19]. The study was conducted in and around the city of Mysore in the South Indian state of Karnataka. The current study was a secondary analysis of data collected as part of the birth cohort study.

\section{Participants}

The participants were born to women recruited into the Mysore Parthenon study. In 1997-1998 pregnant women living in the city of Mysore and surrounding rural areas were recruited to the study if they fulfilled the following criteria: non-diabetic prior to pregnancy; < 32 weeks gestation at time of recruitment; planning to deliver at Holdsworth Memorial Hospital (HMH) and had a singleton pregnancy. Babies were included in the study if they had no major congenital anomalies. Full details of the cohort have been published previously [20]. In brief, 663 women receiving care at the ante-natal clinic of $\mathrm{HMH}$, Mysore, South India gave birth to live singleton babies. Detailed anthropometry of the offspring was obtained within $72 \mathrm{~h}$ of birth and they were followed up every 6 months thereafter.

We asked a subset of the participants to wear accelerometers when they were aged between 6 and 10 years and again at age 11-13 years. When the participants were aged exactly 13.5 years we collected data on risk factors for cardiometabolic disease. Figure 1 shows the flow of participants through the study. 
1997-1998

1,233 eligible pregnant women attending $\mathrm{HMH}$ antenatal clinic

(Singleton, <32 weeks gestation,

not diabetic before pregnancy)

403 women did not participate

830 women participated

Oral glucose tolerance test

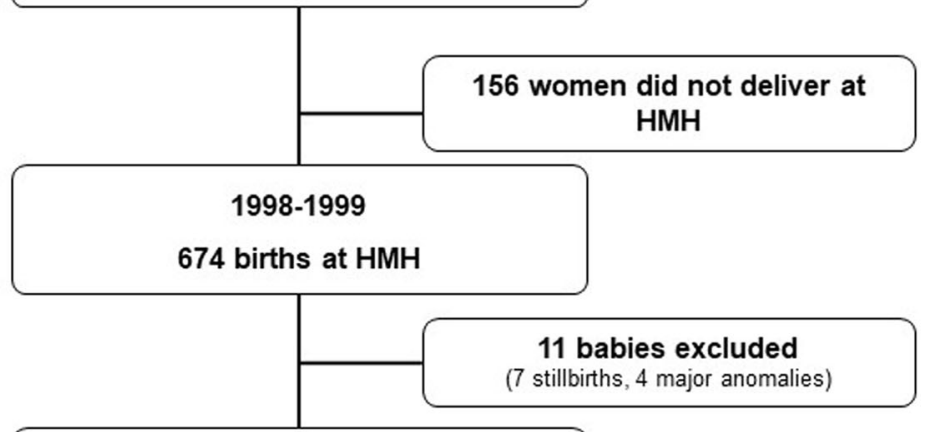

663 live births

Anthropometry, placental measurements, cord blood stored

33 children excluded

( 25 deaths, 8 medically unfit)

630 children eligible for follow-up from

birth

2004-2008

6-10 year physical activity measured

in a subset of the cohort $(\mathrm{N}=449)$

\section{9-2011}

11-13 year physical activity measured

in a subset of the cohort $(\mathrm{N}=431)$

85 children excluded

(73 declined to participate, 12 not traced)

\section{1-2012}

Cardiometabolic risk factor follow-up

at $\mathbf{1 3 . 5}$ years $(\mathrm{N}=545)$

anthropometry, DXA, Blood pressure, fasting glucose, insulin, lipids

Fig. 1 Participant flow chart 
The study was conducted according to the standards of the Declaration of Helsinki. Ethical permission for the study was obtained from the Holdsworth Memorial Hospital Ethics Committee, Mysore. Parents gave informed consent and participants gave assent to take part in the study.

\section{Physical activity}

Accelerometers measure accelerations in a vertical plane and yield data as counts. Counts are used as a proxy for the volume of physical activity the wearer engages in. The volume of physical activity is the product of intensity and duration of physical activity.

A convenience sample of children in the cohort were asked to wear the AM7164 or GT1M actigraph accelerometer (MTI Health Services, Florida, USA) for 7 days at two timepoints, once between the ages of 6-10 years and once between the ages of 11-13 years. The accelerometers weighed approximately $38 \mathrm{~g}$ and were worn at the right hip attached to an elastic belt, they were not waterproof so had to be removed during bathing and water-based activities. The child put the accelerometer on after getting up in the morning and removed it at night before going to bed. Following the measurement period, the accelerometers were returned and the data downloaded and processed using Mahuffe software (MRC Epidemiology Unit, Cambridge, UK). A correction factor was used to ensure that data from the two types of accelerometer was comparable [21] in terms of total counts and counts per minute (cpm).

\section{Cardiometabolic risk factors}

All risk factor measurements were made when the participants were exactly 13.5 years old.

\section{Size and body composition}

The following measurements were made by trained measurers: weight to the nearest $0.1 \mathrm{~kg}$ (Salter digital scales, $\mathrm{UK}$ ); height to the nearest $0.1 \mathrm{~cm}$ (Microtoise, CMS Instruments, UK); waist circumference to the nearest $0.1 \mathrm{~cm}$; triceps and subscapular skinfolds to the nearest $0.1 \mathrm{~mm}$ (Harpenden callipers, CMS Instruments). The inter-observer coefficient of variation (CV) was $<1 \%$ for height and weight, $1.3 \%$ for triceps and $4.5 \%$ for subscapular skinfold thickness.

Bio-impedance analysis was carried out using Bodystat Quadscan 4000 and 1500MDD machines (Bodystat, UK) in order to estimate percentage body fat. Any metal jewellery was removed and participants were asked to lie supine for 5 min before the measurements. After cleaning the skin with surgical spirit, one electrode was attached at the level of the ulnar head at the wrist and the other just behind the knuckles. On the foot, the two electrodes were attached at the level of the medial and lateral malleoli and behind the toes, respectively. This method has been shown to give reliable estimates of fat and fatfree mass [22, 23]. We have observed in a subgroup of the cohort that bio-impedance was useful for measuring group-level changes in adiposity [24].

\section{Insulin resistance and lipid profile}

Glucose, insulin and lipid concentrations (HDL cholesterol, LDL cholesterol and triglycerides) were measured using fasting blood samples. The laboratory assays were carried out at the Diabetes Unit, KEM Hospital, Pune, India, a member of the UK National External Quality Assessment Service (NEQAS) quality control programme for insulin assays. Laboratory staff were blind to the identity of the samples. Plasma glucose and lipid concentrations were measured by standard enzymatic methods (Hitachi902; Roche Diagnostics, Mannheim, Germany). Insulin was measured by ELISA (Mercodia Ultrasensitive; Mercodia, Uppsala, Sweden). Inter- and intra-assay CV was < $7.0 \%$. Insulin resistance was estimated using Homeostasis Model Assessment for insulin resistance (HOMA-IR) [25].

\section{Blood pressure}

Systolic and diastolic blood pressure (BP) were measured using an automated BP monitor (Dinamap 8100, Criticon, FL, USA).

\section{Metabolic syndrome score}

We used the published method of Eisenmann [26] to calculate a metabolic syndrome score in order to obtain a composite score of cardiometabolic risk. The score was the sum of the following variables (all $\mathrm{Z}$ scores with a mean of 0 and a standard deviation of 1 ): waist circumference, mean arterial pressure, ${ }^{1}$ HOMA-IR, triglycerides, ratio of total cholesterol to HDL cholesterol. A higher score indicated greater cardiometabolic risk.

\section{Covariates \\ Gestational diabetes}

The mothers of the participants underwent a $100 \mathrm{~g}, 3 \mathrm{~h}$ oral glucose tolerance test at $30 \pm 2$ weeks gestation. Gestational diabetes was defined using Carpenter and Coustan criteria [27].

\section{Demographic data}

An interviewer-administered questionnaire was used to collect information about socio-economic status using the NFHS-2 Standard of Living Index [28]. The respondent was a parent or close relative.

\footnotetext{
${ }^{1}$ Calculated using the formula $(1 / 3$ mean systolic bp $)+(2 / 3$ mean diastolic bp).
} 


\section{Pubertal staging}

Pubertal status was assessed at 13.5 years by a trained member of the research team using Tanner's method [29], and was classified as the stage of breast development (girls) or genital development (boys).

\section{Data analysis}

Variables that did not approximate a normal distribution were $\log$ transformed for analysis. We used independent $\mathrm{t}$ tests to study the differences between males and females in terms of physical activity and risk factors for cardiometabolic disease.

\section{Physical activity}

The accelerometers were programmed to collect data in 1 min epochs. It was assumed that the monitors had been taken off if zero counts were recorded for a period of more than $20 \mathrm{~min}$. Therefore registered time was defined as all time during which counts were recorded with gaps of no more than $20 \mathrm{~min}$ of consecutive zero $\mathrm{cpm}$. The first and final days of actigraph wearing were not included in the data analysis. Days with less than $500 \mathrm{~min}$ of registered time were considered to be unrepresentative of the participant's physical activity pattern and therefore excluded from further analysis. Allowing for this at least 4 days of data were available for all of the participants. The physical activity variables were in the form of total counts/day and proportion of time spent at different levels of intensity (sedentary, light, moderate and vigorous).

We multiplied counts per day derived from the AM7164 device by 0.91 to allow these variables to be comparable with data from the GT1M device [21]. We present results based on cut offs developed by Evenson et al. [30] $<100 \mathrm{cpm}$ for 'sedentary behaviour', 100$2291 \mathrm{cpm}$ for 'light physical activity'; 2292-4008 cpm for 'moderate physical activity'; $>4008 \mathrm{cpm}$ for 'vigorous physical activity' (V). These categories have been shown to classify physical activity more precisely in children than other published cut offs [31].

\section{Bio-impedance}

Fat percentage values from impedance measurements at $50 \mathrm{kHz}$ were generated using the manufacturer's equation which included terms for sex, age, height and weight.

\section{Physical activity tracking}

We calculated partial Pearson correlation coefficients adjusted for sex and age at first physical activity monitoring to study tracking at the individual level between the two time points at which physical activity was measured.

\section{Statistical procedures}

We used univariate and multivariate linear regression models to study the association between physical activity at both time points and cardiometabolic risk factors at 13.5 years. In the multivariate model we included the following covariates: age at physical activity assessment, sex, pubertal stage at 13.5 years, standard of living, maternal gestational diabetes status.

The data were analysed using SPSS software package version 21 (SPSS Inc., Chicago, IL).

\section{Results}

Between the ages of 6 and 10 years, 449 participants agreed to physical activity monitoring with an accelerometer. Between the ages of 11 and 13 years, 431 agreed to monitoring. At 13.5 years, data were collected from 545 participants on the risk factors for cardiometabolic disease. Of these 545, physical activity data at both time points were available for 290 (Fig. 1).

Table 1 shows the physical activity data collected at both time points by gender. Males were more physically active than females in terms of total volume of physical activity and moderate and vigorous physical activity at both time points. Sedentary time and light physical activity did not differ between sexes at $6-10$ years.

Table 2 shows that there was a correlation between physical activity volume and intensity at both time points indicating that physical activity tracks with age in this population. The correlation was stronger for total volume of physical activity, sedentary time and light physical activity than for moderate and vigorous physical activity indicating that the latter two may not track as closely. This could be due to the relatively low participation in moderate and vigorous activity in this population.

Anthropometric and cardiometabolic disease risk factor data at 13.5 years are presented in Table 3. There were no sex differences in terms of height but females were heavier and had higher body fat percentage and skinfold thickness measurements than males. Females also had a larger waist circumference but smaller waist to hip ratio. In terms of risk factors, females had lower blood pressure, higher insulin and HOMA, and higher total and LDL cholesterol and triglycerides.

Univariate regression models indicated that all measures of physical activity at 6-10 years were negatively associated with body fat percentage (Table 4). These associations were all attenuated in the adjusted models (Table 5). Total counts per day were negatively associated with insulin resistance, body fat percentage, sum of skinfolds and waist circumference in univariate models but only the associations with insulin resistance and body fat percentage remained after adjustment. Moderate physical activity was negatively associated with fat \% and waist circumference in both the unadjusted and 
Table 1 Physical activity measures at 6-10 years and 11-13 years*

\begin{tabular}{|c|c|c|c|c|c|c|}
\hline \multirow{3}{*}{ Physical Activity measures* } & \multicolumn{3}{|l|}{$6-10$ years } & \multicolumn{3}{|l|}{$11-13$ years } \\
\hline & Males & Females & & Males & Females & \\
\hline & $n=140$ & $n=150$ & $p^{\S}$ & $n=175$ & $n=194$ & $p^{\S}$ \\
\hline Counts/ day $\left(\times 10^{3}\right)$ & $448 \pm 128$ & $381 \pm 110$ & $<0.01$ & $418 \pm 144$ & $296 \pm 101$ & $<0.01$ \\
\hline Registered Time (min/d) & $798 \pm 81$ & $783 \pm 77$ & 0.11 & $778 \pm 86$ & $760 \pm 74$ & 0.03 \\
\hline Sedentary (\% of RT) ${ }^{\dagger}$ & $40.7 \pm 9.6$ & $42.6 \pm 9.5$ & 0.51 & $47.9 \pm 11.1$ & $53.6 \pm 10.0$ & $<0.01$ \\
\hline Light physical activity (\% of RT) $^{+}$ & $53.0 \pm 8.3$ & $52.8 \pm 8.7$ & 0.38 & $46.2 \pm 9.6$ & $43.2 \pm 9.2$ & $<0.01$ \\
\hline Moderate physical activity (\% of RT) ${ }^{\dagger}$ & $5.0 \pm 2.2$ & $3.6 \pm 1.7$ & $<0.01$ & $4.7 \pm 2.5$ & $2.8 \pm 1.6$ & $<0.01$ \\
\hline 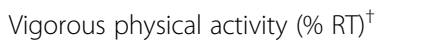 & $1.1(0.5,2.0)$ & $0.8(0.4,1.3)$ & $<0.01$ & $0.8(0.4,1.7)$ & $0.3(0.1,0.6)$ & $<0.01$ \\
\hline
\end{tabular}

*Data are expressed as mean \pm SD for normally distributed variables and as median (IQR) for non-normally distributed variables. ${ }^{\dagger}$ Intensity cut offs are those published by Evenson [30]; CPM Counts per minute, $R T$ registered time ${ }^{\S} p$ value refers to $t$ test of difference between males and females

adjusted models. Vigorous physical activity was negatively associated with insulin resistance, fat percentage, sum of skinfolds, waist circumference and total: HDL cholesterol ratio in both univariate and multivariate models. In the multivariate models, there was a negative association between vigorous physical activity at 610 years and the composite metabolic syndrome score, likewise moderate and vigorous physical activity at 1113 years were inversely associated with the metabolic syndrome score.

\section{Discussion}

We aimed to study the effect of physical activity in childhood and early adolescence on risk factors for cardiometabolic disease at 13.5 years using longitudinal data from a South Indian cohort study [19]. We objectively measured the volume and intensity of physical activity at two time points and looked at tracking of physical activity from childhood to early adolescence. We were unable to make direct comparisons due to differences in ages, methodology and cut points used, but average accelerometer counts per minute were approximately $10-20 \%$ lower in our cohort than among children and adolescents of similar ages in Western countries [10,32]. This supports findings from a global study of physical activity behavior which found Indian children to be among the least physically active in a comparison of 49 countries [18].
We found positive correlations between all of the physical activity variables measured at each of the two time points suggesting that physical activity tracks between childhood and early adolescence in this population. We also found that females were less physically active than males at both time points but particularly in early adolescence. Our data indicated that there may be an association between vigorous physical activity in childhood (610 years) and 13.5 year cardiometabolic disease risk based on a composite metabolic syndrome risk score. Vigorous physical activity at 11-13 years was associated with several risk factors for cardiometabolic disease as well as the composite risk score at 13.5 years. Total physical activity as measured by average total daily accelerometer counts may protect against insulin resistance and adiposity and moderate physical activity was associated with reduced fat percentage and waist circumference as well as the composite risk score. A study in the same cohort exploring associations of linear growth, fat gain and lean tissue gain during different age intervals in infancy and childhood with health-related outcomes at 13.5 years of age showed that faster fat gain in mid-late childhood predicts greater fat percentage and central adiposity, and higher systolic BP and insulin resistance (HOMA-IR) [33]. This fat gain may be a result of dietary exposures but may also be linked to less active lifestyles.

A recent meta-analysis of nine randomised controlled trials found that there was an overall decrease in insulin

Table 2 Tracking of physical activity between childhood and early adolescence; partial Pearson's correlation adjusted for sex and age at 6-10 year measurement $(n=290)$

\begin{tabular}{lllllll}
\hline & \multicolumn{1}{l}{$11-13$ year Physical activity measures } & & \\
\cline { 2 - 7 } & \multicolumn{1}{c}{ Counts/ day } & \% time Sedentary & \% time Light & \% time Moderate & \% time Vigorous \\
\hline 6-10 year Physical activity measures & Counts/day & $0.32^{* *}$ & $-0.24^{* *}$ & $0.20^{*}$ & $0.26^{* *}$ & $0.18^{*}$ \\
& $\%$ time Sedentary & $-0.30^{* *}$ & $0.35^{* *}$ & $-0.33^{* *}$ & $-0.23^{* *}$ & -0.06 \\
& $\%$ time Light & $0.26^{* *}$ & $-0.34^{* *}$ & $0.34^{* *}$ & $0.18^{*}$ & 0.01 \\
& $\%$ time Moderate & $0.24^{* *}$ & $-0.19^{*}$ & $0.14^{*}$ & $0.26^{* *}$ & $0.14^{*}$ \\
& $\%$ time Vigorous & $0.13^{*}$ & -0.07 & 0.03 & $0.14^{*}$ & $0.20^{*}$
\end{tabular}


Table 3 Body composition and chronic disease risk factor measurements at 13.5 years*

\begin{tabular}{|c|c|c|c|}
\hline & Males $(n=175)$ & Females $(n=194)$ & $p^{\S}$ \\
\hline \multicolumn{4}{|l|}{ Measures at $13.5 y$} \\
\hline Weight (kg) & $40.8 \pm 8.3$ & $43.5 \pm 8.4$ & $<0.01$ \\
\hline Height (cm) & $154.4 \pm 8.2$ & $153.5 \pm 5.9$ & 0.22 \\
\hline $\mathrm{BMI}\left(\mathrm{kg} / \mathrm{m}^{2}\right)$ & $16.4(15.4,18.0)$ & $17.9(16.2,20.3)$ & $<0.01$ \\
\hline Waist circumference (cm) & $65.5 \pm 7.7$ & $67.7 \pm 7.9$ & $<0.01$ \\
\hline Waist Hip Ratio & $0.89 \pm 0.05$ & $0.87 \pm 0.05$ & $<0.01$ \\
\hline MUAC (cm) & $21.9 \pm 2.7$ & $22.3 \pm 2.7$ & 0.07 \\
\hline Triceps skin-fold (mm) & $9.6(7.7,14.1)$ & $14.5(11.2,18.4)$ & $<0.01$ \\
\hline Subscapular skin-fold (mm) & $9.2(7.2,13.6)$ & $15.3(11.3,20.3)$ & $<0.01$ \\
\hline Sum of skinfolds (mm) & $18.3(15.0,28.6)$ & $29.4(22.3,39.5)$ & $<0.01$ \\
\hline Fat \% from bio-impedance & $17.6 \pm 6.9$ & $26.1 \pm 5.8$ & $<0.01$ \\
\hline Systolic blood pressure & $110.5 \pm 8.9$ & $107.9 \pm 7.9$ & $<0.01$ \\
\hline Diastolic blood pressure & $62.3 \pm 7.9$ & $58.8 \pm 6.8$ & $<0.01$ \\
\hline Fasting glucose (mmol/L) & $5.07 \pm 0.53$ & $5.02 \pm 0.48$ & 0.39 \\
\hline Fasting insulin (pmol/L) & $33.7(22.4,48.8)$ & $46.1(36.5,64.4)$ & $<0.01$ \\
\hline HOMA-IR & $1.27(0.82,1.80)$ & $1.76(1.35,2.38)$ & $<0.01$ \\
\hline Total cholesterol (mmol/L) & $3.45 \pm 0.69$ & $3.59 \pm 0.62$ & 0.04 \\
\hline $\mathrm{HDL}$ cholesterol $(\mathrm{mmol} / \mathrm{L})$ & $1.07 \pm 0.25$ & $1.06 \pm 0.23$ & 0.52 \\
\hline LDL cholesterol (mmol/L) & $2.01 \pm 0.55$ & $2.13 \pm 0.48$ & 0.04 \\
\hline Triglycerides (mmol/L) & $0.69(0.49,0.98)$ & $0.79(0.60,1.07)$ & 0.02 \\
\hline
\end{tabular}

${ }^{*}$ Values are mean \pm SD for normally distributed variables and median (interquartile range) for non-normally distributed variables. ${ }^{\$} p$ value refers to $t$ test of difference between males and females. MUAC Mid-upper arm circumference, HOMA Homeostasis Model Assessment for insulin resistance

resistance among obese youth aged 6-18 years who were randomised to aerobic exercise interventions. A greater reduction in insulin resistance was observed among those aged 13-18 years than among those 6-12 years [34]. This finding supports our observation that physical activity in earlier childhood is less strongly associated with insulin resistance in adolescence whereas being physically active during early adolescence may be protective. Several crosssectional studies have shown that greater physical activity is associated with reduced adiposity [35-37]. Evidence from a Mendelian Randomisation analysis indicated that increased adiposity causes reduced physical activity but this does not exclude reduced physical activity leading to increased adiposity [32].

Several studies have shown tracking of physical activity across the lifecourse [16, 38]. Although early life physical activity may not be necessary for prevention of later chronic disease, it may be habit-forming and thus children who are active are likely to go on to be active adolescents and adults. A recent study in India assessed the tracking of insulin resistance and measures of adiposity between the ages of 8 and 21 years in the Pune Children's Study cohort [39]. It found that there was strong tracking of BMI, skinfolds and waist circumference and intermediate tracking of insulin resistance and so insulin resistance at 13.5 years is likely to be a risk factor for later diabetes.

The Identification and Prevention of Dietary and lifestyleinduced health Effects in Children and InfantS (IDEFICS) study evaluated cross-sectional associations between physical activity measured using actigraphs and clustering of cardiometabolic risk factors using a score comprised of systolic blood pressure, triglycerides, cholesterol, insulin resistance and cardiorespiratory fitness among 2104 children from 8 European countries (Italy, Estonia, Cyprus, Belgium, Sweden, Germany, Hungary, Spain) aged 6-9 years. Total physical activity and time spent moderately and vigorously active were all negatively correlated with the cardiometabolic risk score [10].

There are several potential mechanisms by which physical activity may reduce cardiometabolic risk. Absence of skeletal muscular contractions is associated with lower blood flow and therefore how efficient many metabolic processes are. For example, reduced transport of circulating glucose to muscle [40, 41]. There is evidence that moderate and vigorous physical activity are associated with increased uptake of glucose by skeletal muscle which leads to decreased blood glucose [42, 43]. It has also been proposed that lack of muscular activity turns off genes that maintain insulin sensitivity [44]. There is also evidence that lack of physical activity produces epigenetic changes including altered DNA methylation which are associated with increased cardiometabolic risk [45]. Furthermore physical activity reduces arterial stiffness and promotes vascular relaxation which may lead to a reduction in blood pressure [42]. In terms of lipid profile, there is evidence that physical activity upregulates enzymes that remove triglycerides and free cholesterol from the circulation and promotes production of HDL cholesterol [46].

It was beyond the scope of this work, but it is important to consider the effect of physical activity on fitness. In a prospective longitudinal study in Canada, participants were recruited at $9-15$ years $(n=315)$ and physical activity was measured using accelerometers. Two years after recruitment, BMI, waist circumference, systolic blood pressure and cardiorespiratory fitness were measured. Time spent in vigorous physical activity was negatively associated with BMI and positively associated with fitness among all children [11]. Increased fitness may lead to increased tracking of vigorous physical activity so it may be that improving and maintaining fitness in early life is an important mechanism for reducing cardiometabolic risk.

\section{Strengths and limitations}

The strengths of our study are that data were collected from a cohort which has been regularly followed up with 


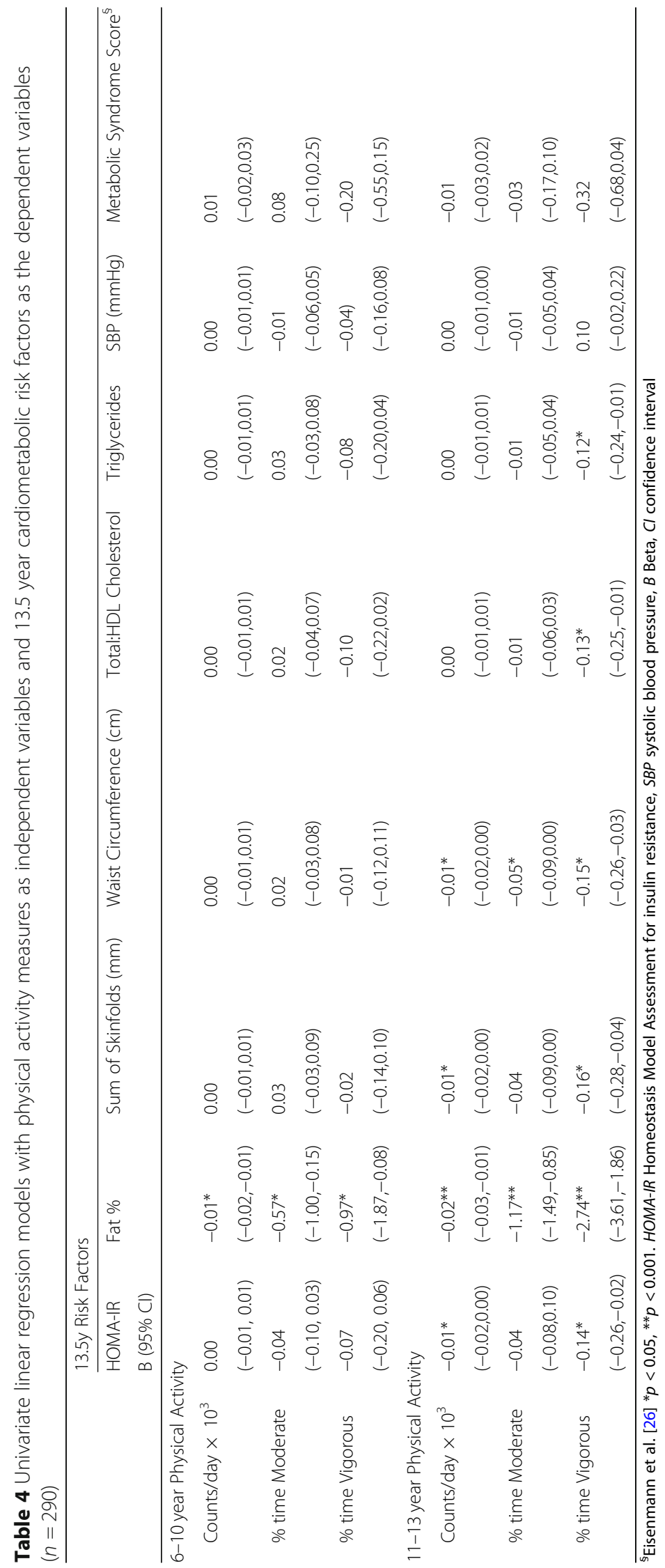




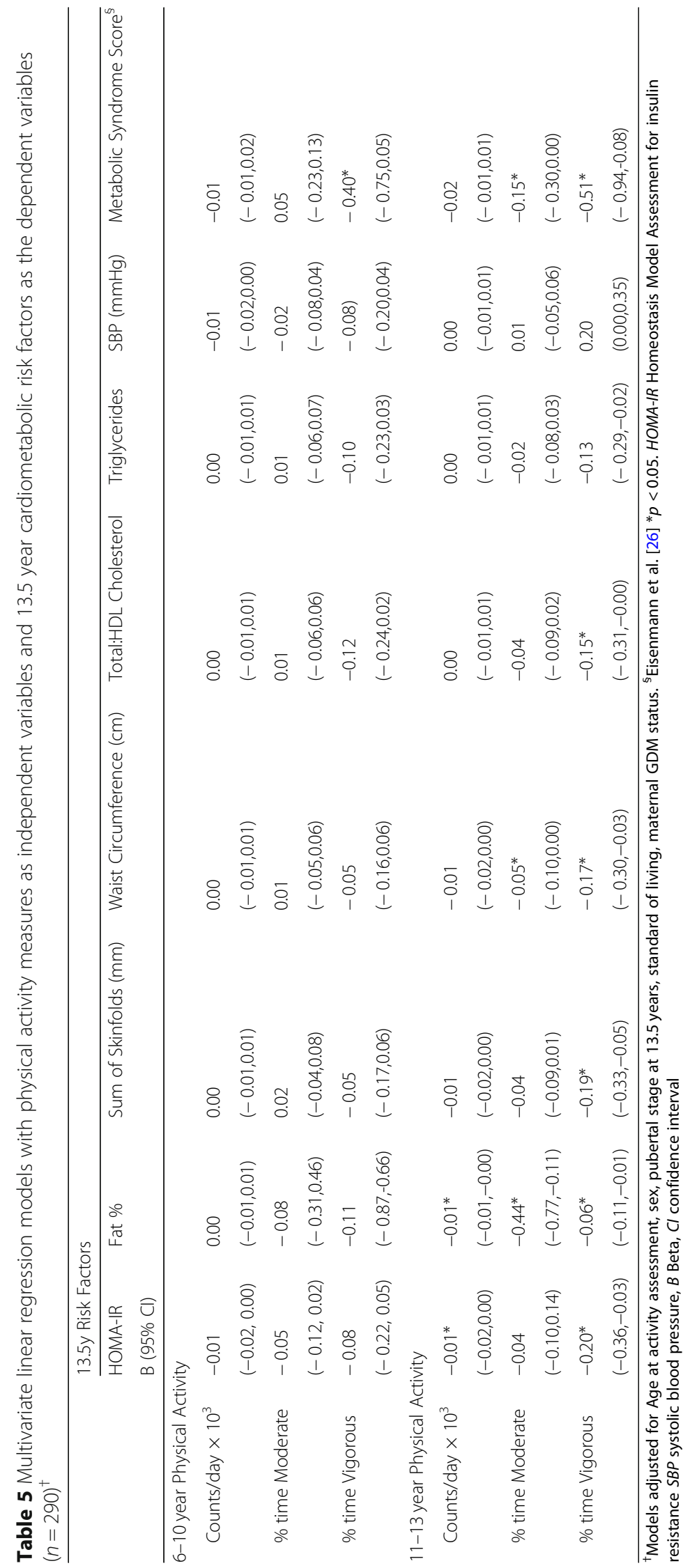


low levels of participant attrition. We measured physical activity objectively in the majority of children within the cohort at two significant time points. This study was a secondary analysis of data collected as part of the birth cohort study and we therefore did not select the time points of measurement a priori. We plan to further assess cardiometabolic outcomes in late adolescence (20 years) in this cohort and look at the associations with physical activity.

A benefit of using accelerometers is that they are an objective method and not subject to recall bias and social desirability issues in the same way that questionnaires or diaries might be. When they are worn at the hip, accelerometers are designed to measure the volume of activities that involve body movements such as walking or running. They are less sensitive to activities that involve little vertical movement at the hip such as cycling, they are also not able to distinguish between movements on the flat versus those on a gradient and cannot be sensitive to activities that involve weights or resistance, for example carrying shopping [47]. It is also possible that there were activities that the children took part in that were not registered by the monitors because they were not worn at all times.

A limitation of our data is that we do not have energy intake at the time of the physical activity measurement so we were unable to adjust for this in our analysis. Energy intake may confound the association between physical activity and insulin resistance.

Furthermore, it is possible that the women and children are not representative of the population in this area. $\mathrm{HMH}$ is a private hospital and mainly caters to families from within the middle socioeconomic stratum of the Mysore population [19]. Therefore the majority of the women were literate and may have been better educated than the representative urban population of the region. However, the characteristics of the mothers during pregnancy and of the offspring at birth and during childhood are similar to those in other urban cohorts in South India [48-50].

\section{Public health implications}

Our findings indicate that interventions are required to promote and increase physical activity among children and adolescents in India and this is supported by national level data $[18,51]$. Implementing such interventions may help to prevent cardiometabolic disease and reduce the increasing health and human capital burden of these chronic conditions. Given our finding that females are less active, it is important that interventions are developed that take into account the challenges that are faced by females in India in this respect. A recent multi-centre study in India and sub-Saharan Africa led by the TALENT consortium (Transforming Adolescent
Lives Through Nutrition) has been conducting qualitative research with adolescents and their caregivers to determine the barriers and facilitators to physical activity among this age group [52]. The ultimate aim of TALENT is to develop and implement interventions to increase activity in collaboration with adolescents and other stakeholders. It is likely that there will be some aspects of physical activity behaviour that can be addressed at the individual level. However, there are also likely to be cultural and structural issues such as pressure to excel academically and walkability difficulties in urban environments that will require a more systemic approach and political will to modify. At present the availability of data on such cultural and structural issues is limited in India $[18,51]$ and a combined approach of collecting such surveillance data and delivering interventions is required to address the rise in cardiometabolic disease.

\section{Conclusions}

Our results indicate that total physical activity and particularly vigorous physical activity in childhood as well as early adolescence may be protective against the risk of cardiometabolic disease. The main finding of this study is that physical activity in early adolescence is associated with a more favorable body composition and cardiometabolic risk profile. To our knowledge this has not been demonstrated in a longitudinal study in India previously. We have shown that physical activity tracks from childhood to early adolescence and that females are less active than males. This finding should be taken into account when developing and implementing interventions. It is arguable that interventions are required at the individual, community and policy level to provide an enabling environment for physical activity and to instill physical activity as a routine behaviour throughout the lifecourse.

\section{Abbreviations}

BF\%: Body fat percentage; BMI: Body mass index; CPM: Counts per minute; CV: Coefficient of variation; CVD: Cardiovascular disease; ELISA: Enzyme-linked immunosorbent assay; HDL: High-density lipoprotein; HMH: Holdsworth Memorial Hospital; HOMA: Homeostatic model assessment; IQR: Inter-quartile range; LDL: Low-density lipoprotein; MUAC: Mid-upper arm circumference; NFHS: National Family Health Survey; PA: Physical activity; RT: Registered time

\section{Acknowledgements}

We thank the study participants and their families, the social workers and research office team at the Epidemiology Research Unit, Holdsworth Memorial Hospital. We acknowledge the work of Dhattatray Bhat and colleagues at the KEM Hospital Diabetes Unit, Pune for the glucose, insulin and lipids measurements. We also thank SNEHA-India for their intellectual support of this work.

\section{Authors' contributions}

GVK, SRV and CHDF conceived and designed the study. GVK, SRV, KNK, SCK and $A D$ acquired the data. SHK, GVK, PC and CHDF analysed and interpreted the data, SHK, GVK and CHDF wrote the first draft of the manuscript and all authors critically reviewed it for intellectual content and contributed to successive drafts. All authors read and approved the final report. 


\section{Funding}

The study was funded by the Parthenon Trust, Switzerland; Wellcome Trust, UK; Medical Research Council, UK. The funders had no role in study design, data collection and analysis or preparation of the manuscript.

\section{Availability of data and materials}

The datasets generated and analysed during the current study are not publicly available due to Government of India regulations. However, the Parthenon Cohort team is open to data sharing with bona fide researchers on request subject to relevant Government of India permissions and ethics approval. For further information contact the corresponding author.

\section{Ethics approval and consent to participate}

The Holdsworth Memorial Hospital Ethics Committee gave approval for the study; informed written consent from parents and assent from children were obtained.

\section{Consent for publication}

Not applicable

\section{Competing interests}

The authors declare that they have no competing interests.

\section{Author details}

${ }^{1}$ Medical Research Council Lifecourse Epidemiology Unit, Southampton General Hospital, Tremona Road, Southampton SO16 6YD, UK. Epidemiology Research Unit, Holdsworth Memorial Hospital, Mandi Mohalla, Mysuru, Karnataka 570021, India.

\section{Received: 10 October 2018 Accepted: 25 November 2019}

Published online: 18 December 2019

\section{References}

1. Institute for Health Metrics and Evaluation. Findings from the Global Burden of Disease Study 2017. Seattle: Institute for Health Metrics and Evaluation; 2018.

2. Patel V, Chatterji S, Chisholm D, Ebrahim S, Gopalakrishna G, Mathers C, Mohan V, Prabhakaran D, Ravindran RD, Reddy KS. Chronic diseases and injuries in India. Lancet. 2011;377(9763):413-28.

3. International Diabetes Federation. IDF Diabetes Atlas, 7th edn. Brussels; 2015

4. World Health Organisation. The world health report 2007 - A safer future: global public health security in the 21st century. Geneva; 2007.

5. Lobstein T, Baur L, Uauy R. Obesity in children and young people: a crisis in public health. Obes Rev. 2004;5(Suppl 1):4-104.

6. Kumar S, Mahabalaraju DK, Anuroopa MS. Prevalence of obesity and its influencing factor among affluent school children of Davangere city. Indian J Community Med. 2007;32(1):15-7.

7. Misra A, Khurana L, Vikram NK, Goel A, Wasir JS. Metabolic syndrome in children: current issues and South Asian perspective. Nutrition. 2007;23(1112):895-910.

8. Whincup PH, Gilg JA, Papacosta O, Seymour C, Miller GJ, Alberti KG, Cook DG. Early evidence of ethnic differences in cardiovascular risk: cross sectional comparison of British South Asian and white children. BMJ. 2002; 324(7338):635

9. Bhardwaj S, Misra A, Khurana L, Gulati S, Shah P, Vikram NK. Childhood obesity in Asian Indians: a burgeoning cause of insulin resistance, diabetes and sub-clinical inflammation. Asia Pac J Clin Nutr. 2008;17(Suppl 1):172-5.

10. Jimenez-Pavon D, Konstabel K, Bergman P, Ahrens W, Pohlabeln H, Hadjigeorgiou C, Siani A, lacoviello L, Molnar D, De Henauw S, et al. Physical activity and clustered cardiovascular disease risk factors in young children: a cross-sectional study (the IDEFICS study). BMC Med. 2013;11:172.

11. Carson V, Rinaldi RL, Torrance B, Maximova K, Ball GD, Majumdar SR, Plotnikoff RC, Veugelers P, Boule NG, Wozny P, et al. Vigorous physical activity and longitudinal associations with cardiometabolic risk factors in youth. Int J Obes. 2014;38(1):16-21.

12. Andersen LB, Harro M, Sardinha LB, Froberg K, Ekelund U, Brage $S$, Anderssen SA. Physical activity and clustered cardiovascular risk in children: a cross-sectional study (The European Youth Heart Study). Lancet. 2006; 368(9532):299-304

13. Carson V, Hunter S, Kuzik N, Gray CE, Poitras VJ, Chaput JP, Saunders TJ, Katzmarzyk PT, Okely AD, Connor Gorber S, et al. Systematic review of sedentary behaviour and health indicators in school-aged children and youth: an update. Appl Physiol Nutr Metab. 2016:41(6 Suppl 3):S240-65.

14. Andersen LB, Riddoch C, Kriemler S, Hills AP. Physical activity and cardiovascular risk factors in children. Br J Sports Med. 2011:45(11):871-6.

15. Ried-Larsen M, Grontved A, Moller NC, Larsen KT, Froberg K, Andersen LB. Associations between objectively measured physical activity intensity in childhood and measures of subclinical cardiovascular disease in adolescence: prospective observations from the European Youth Heart Study. Br J Sports Med. 2014;48(20):1502-7.

16. Craigie AM, Lake AA, Kelly SA, Adamson AJ, Mathers JC. Tracking of obesityrelated behaviours from childhood to adulthood: a systematic review. Maturitas. 2011;70(3):266-84

17. Azevedo MR, Araujo CL, Cozzensa da SM, Hallal PC. Tracking of physical activity from adolescence to adulthood: a population-based study. RevSaude Publica. 2007:41(1):69-75.

18. Aubert S, Barnes JD, Abdeta C, Abi Nader P, Adeniyi AF, Aguilar-Farias N, Andrade Tenesaca DS, Bhawra J, Brazo-Sayavera J, Cardon G, et al. Global matrix 3.0 physical activity report card grades for children and youth: results and analysis from 49 countries. J Phys Act Health. 2018; 15(S2):S251-s273.

19. Krishnaveni GV, Veena SR, Hill JC, Karat SC, Fall CH. Cohort profile: Mysore parthenon birth cohort. Int J Epidemiol. 2015;44(1):28-36.

20. Krishnaveni GV, Hill JC, Veena SR, Leary SD, Saperia J, Chachyamma KJ, Karat SC, Fall CH. Truncal adiposity is present at birth and in early childhood in South Indian children. Indian Pediatr. 2005;42(6):527-38.

21. Corder K, Brage S, Ramachandran A, Snehalatha C, Wareham N, Ekelund U. Comparison of two Actigraph models for assessing free-living physical activity in Indian adolescents. J Sports Sci. 2007;25(14):1607-11.

22. Bray GA, DeLany JP, Harsha DW, Volaufova J, Champagne CC. Evaluation of body fat in fatter and leaner 10-y-old African American and white children: the Baton Rouge Children's Study. Am J Clin Nutr. 2001;73(4):687-702.

23. Pietrobelli A, Andreoli A, Cervelli V, Carbonelli MG, Peroni DG, De Lorenzo A Predicting fat-free mass in children using bioimpedance analysis. Acta Diabetol. 2003:40(Suppl 1):S212-5.

24. Kehoe SH, Krishnaveni GV, Lubree HG, Wills AK, Guntupalli AM, Veena SR, Bhat DS, Kishore R, Fall CH, Yajnik CS, et al. Prediction of body-fat percentage from skinfold and bio-impedance measurements in Indian school children. Eur J Clin Nutr. 2011:65(12):1263-70.

25. Matthews DR, Hosker JP, Rudenski AS, Naylor BA, Treacher DF, Turner RC. Homeostasis model assessment: insulin resistance and beta-cell function from fasting plasma glucose and insulin concentrations in man. Diabetologia. 1985;28(7):412-9.

26. Eisenmann JC. On the use of a continuous metabolic syndrome score in pediatric research. Cardiovasc Diabetol. 2008;7:17.

27. Carpenter MW, Coustan DR. Criteria for screening tests for gestational diabetes. Am J Obstet Gynecol. 1982;144(7):768-73.

28. International Institute for Population Sciences. National Family Health Survey (NFHS-2) 1998-1999. Mumbai/Washington, DC; 2000

29. Tanner JM. Growth in adolescence. 2nd ed. Oxford: Blackwell Scientific Publications; 1962

30. Evenson KR, Catellier DJ, Gill K, Ondrak KS, McMurray RG. Calibration of two objective measures of physical activity for children. J Sports Sci. 2008:26(14):1557-65.

31. Trost SG, Loprinzi PD, Moore R, Pfeiffer KA. Comparison of accelerometer cut points for predicting activity intensity in youth. Med Sci Sports Exerc. 2011;43(7):1360-8.

32. Richmond RC, Davey Smith G, Ness AR, den Hoed M, McMahon G, Timpson NJ. Assessing causality in the association between child adiposity and physical activity levels: a Mendelian randomization analysis. PLoS Med. 2014; 11(3):e1001618

33. Krishnaveni GV, Veena SR, Srinivasan K, Osmond C, Fall CH. Linear growth and fat and lean tissue gain during childhood: associations with cardiometabolic and cognitive outcomes in adolescent Indian children. PLoS One. 2015:10(11):e0143231.

34. Garcia-Hermoso A, Saavedra JM, Escalante Y, Sanchez-Lopez M, MartinezVizcaino V. Endocrinology and adolescence: aerobic exercise reduces insulin resistance markers in obese youth: a meta-analysis of randomized controlled trials. Eur J Endocrinol. 2014:171(4):R163-71.

35. Ness AR, Leary SD, Mattocks C, Blair SN, Reilly JJ, Wells J, Ingle S, Tilling K, Smith GD, Riddoch C. Objectively measured physical activity and fat mass in a large cohort of children. PLoS Med. 2007;4(3):e97. 
36. Ekelund U, Sardinha LB, Anderssen SA, Harro M, Franks PW, Brage S, Cooper AR, Andersen LB, Riddoch C, Froberg K. Associations between objectively assessed physical activity and indicators of body fatness in 9- to 10-y-old European children: a population-based study from 4 distinct regions in Europe (the European Youth Heart Study). Am J Clin Nutr. 2004;80(3):584-90.

37. Trost SG, Sirard JR, Dowda M, Pfeiffer KA, Pate RR. Physical activity in overweight and nonoverweight preschool children. Int J Obes Relat Metab Disord. 2003;27(7):834-9.

38. McMullen S. Childhood obesity: the impact on long-term risk of metabolic and CVD is not necessarily inevitable. Proc Nutr Soc. 2014;73(3):389-96.

39. Joshi SM, Katre PA, Kumaran K, Joglekar C, Osmond C, Bhat DS, Lubree H, Pandit A, Yajnik CS, Fall CH. Tracking of cardiovascular risk factors from childhood to young adulthood - the Pune Children's Study. Int I Cardiol. 2014;175(1):176-8.

40. Verswijveren S, Lamb KE, Bell LA, Timperio A, Salmon J, Ridgers ND. Associations between activity patterns and cardio-metabolic risk factors in children and adolescents: a systematic review. PLoS One. 2018;13(8): e0201947.

41. Tremblay MS, Colley RC, Saunders TJ, Healy GN, Owen N. Physiological and health implications of a sedentary lifestyle. Appl Physiol Nutr Metab. 2010; 35(6):725-40.

42. Figueiro TH, Arins GCB. Association of objectively measured sedentary behavior and physical activity with cardiometabolic risk markers in older adults. PLOS One. 2019;14(1):e0210861.

43. Holloszy JO. Exercise-induced increase in muscle insulin sensitivity. J Appl Physiol (Bethesda, MD: 1985). 2005;99(1):338-43.

44. Hamilton MT, Hamilton DG, Zderic TW. Exercise physiology versus inactivity physiology: an essential concept for understanding lipoprotein lipase regulation. Exerc Sport Sci Rev. 2004;32(4):161-6.

45. Cheng Z, Zheng L, Almeida FA. Epigenetic reprogramming in metabolic disorders: nutritional factors and beyond. J Nutr Biochem. 2018;54:1-10.

46. Mann S, Beedie C, Jimenez A. Differential effects of aerobic exercise, resistance training and combined exercise modalities on cholesterol and the lipid profile: review, synthesis and recommendations. Sports Med. 2014; 44(2):211-21.

47. Hendelman D, Miller K, Baggett C, Debold E, Freedson P. Validity of accelerometry for the assessment of moderate intensity physical activity in the field. Med Sci Sports Exerc. 2000;32(9 Suppl):S442-9.

48. Muthayya S, Dwarkanath P, Thomas T, Vaz M, Mhaskar A, Mhaskar R, Thomas A, Bhat S, Kurpad A. Anthropometry and body composition of south Indian babies at birth. Public Health Nutr. 2006;9(7):896-903.

49. Bavdekar A, Yajnik CS, Fall CH, Bapat S, Pandit AN, Deshpande V, Bhave S, Kellingray SD, Joglekar C. Insulin resistance syndrome in 8-year-old Indian children: small at birth, big at 8 years, or both? Diabetes. 1999:48(12):2422-9.

50. Ranjani H, Sonya J, Anjana RM, Mohan V. Prevalence of glucose intolerance among children and adolescents in urban South India (ORANGE-2). Diabetes Technol Ther. 2013;15(1):13-9.

51. Katapally TR, Goenka S, Bhawra J, Mani S, Krishnaveni GV, Kehoe SH, Lamkang AS, Raj M, McNutt K. Results from India's 2016 report card on physical activity for children and youth. J Phys Act Health. 2016;13(11 Suppl 2):S176-s182.

52. [https://www.southampton.ac.uk/global-health/research/lifecourseepidemiology/talent/talent-home.page]

\section{Publisher's Note}

Springer Nature remains neutral with regard to jurisdictional claims in published maps and institutional affiliations.

Ready to submit your research? Choose BMC and benefit from:
- fast, convenient online submission
- thorough peer review by experienced researchers in your field
- rapid publication on acceptance
- support for research data, including large and complex data types
- gold Open Access which fosters wider collaboration and increased citations
- maximum visibility for your research: over 100M website views per year
At BMC, research is always in progress.
Learn more biomedcentral.com/submissions

